\title{
Estatuto jurídico de los animales en el Código civil. La esperada descosificación animal
}

\author{
Marita Giménez-Candela \\ Catedrática \\ Directora del ICALP y del Máster en Derecho Animal UAB \\ ORCID: 0000-0002-0755-5928 \\ SCOPUS ID: 57218923647
}

Recepción: Junio 2021

Aceptación: Junio 2021

Cita recomendada. GIMÉNEZ-CANDELA, M., Estatuto jurídico de los animales en el Código civil. La esperada descosificación animal, dA. Derecho Animal (Forum of Animal Law Studies) 12/2 (2021). - DOI https://doi.org/10.5565/rev/da.582

\section{Resumen}

El estatuto jurídico de los animales en el Código civil español está necesitado de una modificación que actualice y modernice su tratamiento y lo adecúe a las necesidades y demandas de la sociedad. En este trabajo se abordan los puntos clave de dicha modificación que está actualmente en tramitación, en espera después de haberse interrumpido la propuesta inicial por circunstancias políticas sobrevenidas-, desde el año 2017 en que el Parlamento aprobó el reconocimiento de los animales en el Código civil como seres sentientes, en lugar de cosas tal y como figura en la actual redacción, lo que en principio permite asimilarlos a los objetos inertes. Se aborda esta cuestión, dentro del contexto del actual movimiento de descosificación de los animales, que ha encontrado ya eco en varios países europeos y latinoamericanos.

Palabras clave: Estatuto jurídico animal, Código civil español, Codificación. Derecho continental, concepto de animal, seres sentientes, sentiencia animal, art. 13 TFUE, bienestar animal.

\section{Abstract - The legal status of animals in the Civil Code: The long-awaited de-objectification of animals}

The legal status of animals in the Civil Code is in need of a modification that updates and modernises their treatment and ensures it meets the needs and demands of society. This work addresses the key points of the modification that, the initial proposal having been interrupted by unexpected political circumstances, is still underway, awaited since 2017 when the parliament approved the Civil Code recognition of animals as sentient beings, as opposed to things, as they appear in the current version, which ultimately allows them to be assimilated with inert objects. The topic will be addressed within the context of the current movement to deobjectify animals that has already taken off in various European and Latin-American countries.

Keywords: Legal status of animals, Spanish Civil Code, Codification, Continental Law, concept of animal, sentient beings, animal sentience, art. 13 TFEU, animal welfare. 


\section{Sumario}

1. Los antecedentes

2. Las claves de la propuesta de modificación del Código civil. Descosificación

3. Los posibles efectos de la modificación en curso

\section{Los antecedentes}

El Código civil español, como muchos otros Códigos civiles coetáneos ${ }^{1}$, es heredero del impulso codificador que barrió Europa y Latinoamérica después de que Napoleón decidiera culminar el proceso revolucionario más importante de la historia contemporánea, la Revolución Francesa, haciendo suyo el postulado de dotar de un nuevo derecho a un nuevo hombre -el ciudadano-, libre de las ataduras del Antiguo Régimen ${ }^{2}$. El Código Napoleón ${ }^{3}$ es, como suele aceptarse, un Código revolucionario. La Codificación como secuela del impulso napoleónico, fue el trasfondo jurídico que sirvió de instrumento para liderar el proceso revolucionario de liberación colonial de muchos países de Latinoamérica: un nuevo derecho para un nuevo pueblo -una ciudadanía-, libre de las ataduras de la Colonia, que venía a ser un trasunto del Antiguo Régimen.

Curiosamente este mismo marco mental e ideológico -la culminación de un proceso de cambio-, ha servido de forma recurrente para justificar la Codificación del Derecho en países que exteriorizaban con ello un proceso revolucionario, al menos en el sentido en que ese término se emplea incluso para caracterizar los movimientos de liberación colonial del S. XIX. Es el caso de los Códigos civiles de Turquía ${ }^{4}$ o de Japón ${ }^{5}$, o actualmente de $\mathrm{China}^{6}$, tan distantes no sólo geográficamente sino también ideológicamente de los movimientos de liberación latinoamericanos. También en estos países, la Codificación del Derecho Civil ha sido el instrumento para visibilizar una voluntad de cambio respecto a la tradición anterior y una forma de declarar la voluntad modernizadora de la ciudadanía.

En todos los Códigos civiles a los que hago referencia, el sustrato de la reunión y ordenación de las materias, con algunas variantes, responde a la gran tradición jurídica romana que, con todos sus avatares, fue el derecho común (ius commune) por excelencia de todos los pueblos que alguna vez fueron territorio del llamado Imperio Romano ${ }^{7}$. En otros términos, el Código civil, cualquier Código civil dentro del ámbito que conocemos como Civil Law, reproduce las instituciones romanas e incluso el orden romano de la exposición de las materias con que el emperador Justiniano ordenó compilar ("saquear") las obras de la antigua Jurisprudencia romana ${ }^{8}$. Un orden de materias que no hacía sino reproducir la secuencia del orden seguido por el Edicto del Pretor ${ }^{9}$. En ese sentido, también el Código civil español es de tradición romana y reproduce las instituciones básicas para la resolución de conflictos, creadas con base en las opiniones de los juristas romanos.

\footnotetext{
${ }^{1}$ El Código civil de los franceses de 1804 (Code civil des Français) se adoptó, ajustó o tuvo influencia en Europa y Latinoamérica ya en el S. XIX: Bélgica (1804), Polonia (1804), Luisiana (1808), Países Bajos (1810), Haití (1826), Bolivia (1831), Chile (1855), Ecuador (1861), Romania (1864), Italia (1865), Portugal (1865), Quebec (1866), Argentina (1869), México (1870), Uruguay (1871), Colombia (1887), Paraguay (1889), España (1889). Sobre este tema, vid. también, GRIMALDI, M., L'exportation du code civil, en Pouvoirs. Revue française d'études constitutionnelles et politiques 107 (2003/4) 80-96.

${ }^{2}$ HALPÉRIN, J.L., L'Histoire de la fabrication du Code. Le Code Napoleon, en Pouvoirs. Revue Française d'études constitutionelles et politiques $107(2003 / 4) 11$ ss.

${ }^{3}$ El Código civil de los franceses de 1804 se llamó oficialmente Código Napoleón (Code Napoléon) en 1807 (Décret du 3 septembre 1807).

${ }^{4}$ El Código civil turco de 1926 se basó en el Código civil suizo de 1907. Vid. OGUZ, A., The Role of Comparative Law in the development of Turkish Civil Law, en Pace Int'l L. Rev. 17 (2005) 373-386.

${ }^{5}$ Primer código asiático, el Código civil japonés entró en vigor en 1898. Vid. JALUZOT, B., Les origines du code civil japonais, en Zeitschrift für Japanisches Recht Journal of Japanese Law (2015) 121-146

${ }^{6}$ El Código civil de China entró en vigor el 1 de enero de 2021. Se trata de texto directamente fundado en el Derecho romano (especialmente el Corpus Juris Civilis que se compiló por impulso del emperador Justiniano) sin pasar por la codificación napoleónica, como ocurrió en los códigos civiles de otros países. Sobre esta novedad, vid. CARDILLI, R., PORCELLI, S., Introduzione al diritto cinese (Torino 2020).

${ }^{7}$ GIMÉNEZ-CANDELA, T., Derecho Privado Romano (Valencia 2020) 35, 37, $38,42$.

${ }^{8}$ Ibíd., 106 ss.

${ }^{9}$ Ibíd., 8, 78, 108, 117.

8 Derecho Animal. Forum of Animal Law Studies, vol. 12/2
} 
Ninguna sorpresa, pues, que el régimen jurídico de los animales que aparece plasmado en el Código civil de España (y en los demás Códigos civiles herederos del Código Napoleón), siga las pautas romanas del tratamiento que se dio a los animales en la Roma clásica. Dicho tratamiento consistió fundamentalmente, dicho sea aquí de forma sintética ${ }^{10}$, en incluir a los animales dentro de la categoría jurídica de las cosas en propiedad. Poco relieve se ha dado en la literatura especializada a este hecho fundamental, diferenciador, relativo al tratamiento jurídico romano acerca de los animales por el que estos, junto con los esclavos, se "cosifican", es decir, entran a formar parte, como categoría jurídica diferenciada, de la institución de la propiedad. Que en Roma, por primera vez se incluya a los animales como realidad jurídica y se les coloque dentro de una institución indiscutida como es la propiedad ${ }^{11}$, es un hallazgo del genio jurídico romano pues no hay rastro de tal categorización jurídica de los animales en otros regímenes jurídicos de otros pueblos de la Antigüedad. Dicha inclusión de los animales y los esclavos en el marco de las cosas en propiedad, era perfectamente adecuado a una sociedad eminentemente rural como la romana ${ }^{12}$.

Precisamente, que cuando hablamos de modificación del estatuto jurídico de los animales hoy en día, se argumente la necesidad de modernización del estatuto jurídico de los mismos ${ }^{13}$, tiene que ver con la inadecuación de tal estatuto a una sociedad como la nuestra, que no es precisamente una sociedad rural. No obstante, no se debe simplificar en exceso esta consideración, pues a los animales, independientemente de encontrar acomodo (o no) en el régimen de la propiedad, no se les puede tratar como cosas inertes, sencillamente porque como la ciencia ha demostrado sobradamente, no lo $\operatorname{son}^{14}$. Al contrario, los animales son seres con capacidades, consciencia y sentiencia muy semejantes a los nuestros ${ }^{15}$. Así lo ha refrendado la Ciencia del Bienestar animal y así ha sido acogido por el art. 13 TFUE desde el año $2009^{16}$.

El tratamiento jurídico de los animales ha tropezado de forma recurrente con una dificultad de fondo, que no es otra que el legislador nunca ha definido de forma clara y precisa qué se entiende por animal en el Derecho. De hecho, ninguna referencia existe sobre el concepto de animal en la literatura relativa ${ }^{17}$, salvo las observaciones que en su momento realicé ${ }^{18}$ a propósito de la necesidad de crear una referencia de carácter jurídico que abarque la diversidad animal y no sea excluyente. Con cierto hartazgo, algunos reconocidos especialistas en las ciencias del bienestar animal se niegan a usar la distinción "animales humanos y "animales no-humanos"19. Bien sabido es que el ser humano es un animal, pero quizá la sencillez de la denominación que se hace servir para referirse al hombre y al animal, tal como se hace en los textos de la Antigüedad clásica sea preferible y baste con decir animal para que se sepa que nos referimos a la inmensa diversidad del reino

\footnotetext{
${ }^{10}$ De forma detallada, vid. GIMÉNEZ-CANDELA, M., Transición animal en España (Valencia 2020) 148, 174, 182, 231: GIMÉNEZCANDELA, T., Derecho Privado Romano (cit.) 19, 20, 165, 166, 168, 169, 170, 171

${ }^{11}$ De la vasta literatura acerca de la propiedad, sólo destacaré aquí dos estudios con perspectiva crítica y una proyección teórica que va más allá de los acostumbrados repertorios normativos: HALPERIN, J.L., Histoire du Droit des Biens (Paris 2008), quien pone de relieve que se debe a Roma la sistematización del derecho de propiedad, con base en la conocida clasificación gaiana de las cosas; y SCHERMAIER, M., Dominus actuum suorum. Die willenstheoretische Begründung des Eigentums und das römische Recht, en SZ 134 (2017) 50ss.

12 CAPOGROSSI COLOGNESI, L., Das Eigentum in Rom vom Ende der patriarchalischen Ordnung bis zur Blütezeit der Sklavereiordnung, en Scritti scelti (Roma 2010) 299-323; RATHBONE, D., Rural Economy and Society in Roman Italy (Cambridge University Press 2004); REMESAL RODRÍGUEZ, J., Heeresversorgung im frühen Prinzipat. Eine Art, die antike Wirtschaft zu verstehen. (Münster 2002); SCHEIDEL, W., von REDEN, S. (ed.) The Ancient Economy (Princeton 2002); FINLEY, M.I., Ancient Economy (California University Press 1999); DUNCAN-JONES, R., Structure \& Scale in the Roman Economy (Cambridge University Press 1990); WEBER, M., Wirtschaft und Gesellschaft: Grundriß der verstehende Soziologie/Max Weber; besorgt von Johannes Winckelmann (Tübingen 1985)

${ }^{13}$ El llamado Amendement Glavany por el nombre de uno de los diputados que presentó la propuesta de reforma, hizo uso de un proyecto general de "modernización" de la legislación francesa, para introducir el cambio de estatuto jurídico de los animales de cosas a "êtres vivants doués de sensibilité": Proyecto de Ley de modernización y simplificación del Derecho en los ámbitos de la Justicia y Asuntos de Interior (No. 1808) https://www.assemblee-nationale.fr/14/amendements/1808/AN/59.asp. Vid. con visión pionera, desde 2009, MARGUÉNAUD, J.P. Avant-Propos, en RSDA 1 (2009) 7ss.; ANTOINE, S., Le projet de réforme du droit des biens, en RSDA 1 (2009) 11ss; MARGUÉNAUD, J.P., L'entrée en vigueur de "l'amendement Glavany": un grand pas de plus vers la personnalité juridique des animaux, RSDA 2/2014, 15ss.

${ }^{14}$ Vid, infra n. 28

15 De la sentiencia animal, como elemento clave para aplicar mejoras en el tratamiento jurídico de los animales, me ocupo en, GIMÉNEZ-CANDELA, M., Dignidad, Sentiencia, Personalidad: relación jurídica humano-animal, en dA, Derecho Animal, (Forum of Animal Law Studies) 9/2 (2018) 5-16. https://doi.org/10.5565/rev/da.346

16 Art. 13 del Tratado de Funcionamiento de la Unión Europea : "Al formular y aplicar las políticas de la Unión en materia de agricultura, pesca, transporte, mercado interior, investigación y desarrollo tecnológico y espacio, la Unión y los Estados miembros tendrán plenamente en cuenta las exigencias en materia de bienestar de los animales como seres sensibles, respetando al mismo tiempo las disposiciones legales o administrativas y las costumbres de los Estados miembros relativas, en particular, a ritos religiosos, tradiciones culturales y patrimonio regional.”

${ }^{17}$ Una llamada de atención sobre esta ausencia de definición del animal en el ámbito jurídico aparece en dos autores, LE BOT, O., La protection de l'animal en droit constitutionnel. Etude de droit comparé, en RRJ 2007/4, 1823ss.; y FRASCH, P. (et al.), Animal Law in a Nutshell (Ann Arbor, Michigan 2011) 4ss.

${ }^{18}$ GIMÉNEZ-CANDELA, M., Transición animal en España (cit.) 159ss.

${ }^{19}$ CHAPOUTHIER, G., KAPLAN, F., L'homme, l'animal et la machine (Paris 2011) 7s.; 203ss.
} 
animal, que comprende desde los elefantes a los mosquitos ${ }^{20}$.

La definición del animal es, en dicho sentido, poliédrica y cambiante. Es también de una vastedad semántica que la hace prácticamente inabarcable. No obstante, conviene que nos fijemos en qué sentido o sentidos usamos el término animal, pues es un aspecto medular de lo que aquí se discute. Independientemente de las connotaciones filosóficas y sociales que el término animal tiene ${ }^{21}$, cuando nos referimos a los animales nos referimos a una realidad que puebla nuestras vidas, pero también el arte, la ciencia, la gastronomía, la religión, el imaginario colectivo y la actividad política a escala global ${ }^{22}$.

Aunque la percepción directa y espontánea, biológica, de qué es un animal parece evidente ${ }^{23}$, no lo es tanto en los textos jurídicos. Durante siglos los animales se han identificado en los textos jurídicos con las cosas, en razón del estatuto jurídico con el que el hombre los ha sistematizado, desde la inclusión romana de los animales en el sistema jurídico como res $(=\operatorname{cosa})$ en propiedad al igual que los esclavos ${ }^{24}$, tal como se ha referido. Hoy en día ésta es, sin embargo, una categoría jurídica en franca descomposición y cambio. El tránsito de la cosificación animal, vigente e indiscutida durante siglos, se ha convertido en las últimas décadas en un proceso de descosificación del animal en los textos jurídicos, que parece imparable y tiene carácter global ${ }^{25}$.

La connotación etimológica del término animal con anima (alma $)^{26}$-tan obvia como imprescindible-, sirve para entender que el ser animado (=con alma), insuflado de un hálito de vida, comprende también al ser humano, pero se usa habitualmente para hacer referencia a todo ser vivo distinto de las plantas que son seres sésiles (como también algunos animales como el coral o los moluscos), mientras que el animal se mueve y recorre el planeta lo mismo que nosotros.

Que la atribución biológica del parentesco inescindible entre hombre y animal sea un dato indiscutido desde Darwin ${ }^{27}$, no ha evitado la resistencia del Derecho a reconocer la inteligencia animal y sus indudables capacidades de conocimiento y consciencia ${ }^{28}$. Es más, de la negativa a atribuir al animal algo más que capacidad corporal-física de percibir estímulos sensoriales para, consecuentemente, encuadrarlos dentro de la categoría de las cosas (asimilados a las cosas inertes), se ha hecho el eje de la diferencia entre el hombre (dotado de razón y de capacidad de hablar) y el animal. Ésta ha sido, desde la Antigüedad, la perspectiva dominante en la cultura y el pensamiento filosófico ${ }^{29}$. Como con acierto observa recientemente POLLO ${ }^{30}$, en el S. XVIII empieza a quebrarse dicho eje diferenciador hombre-animal, anclado férreamente en la afirmación de ciertas capacidades humanas como el habla o el raciocinio, para ser sustituido de forma progresiva por lo que dicho autor denomina un "Iluminismo de los sentimientos", cuyos primeros representantes son Bentham ${ }^{31}$

\footnotetext{
${ }^{20}$ CHAPOUTHIER, G., Qu'est-ce que l'animal? (Paris 2004)

${ }^{21}$ Por todos, POLLO, S., Umani e Animali. Questioni di Etica (Roma 2016); MANNUCCI, E.J., La cena di Pitagora. Storia del vegetarianismo dall'antica Grecia a Internet (Roma 2008); ATTERTON P., CALARCO, M., Animal Philosophy. Ethics and Identity (London-New York 2004).

${ }^{22}$ Vid. con esta perspectiva el conjunto de estudios interdisciplinares, AAVV, Les animaux, en Pouvoirs. Revue Française d'études constitutionnelles et politiques 131 (2009/4) 1-209

${ }^{23}$ Vid. una reciente aproximación, STAMP DAWKINS, M., The Science of Animal Welfare. Understanding what animals want (Oxford 2021).

${ }^{24}$ GIMÉNEZ-CANDELA, T., Derecho Privado Romano (cit.) 48, 165, 166, 225ss.; GIMÉNEZ-CANDELA, M., La Descosificación de los animales (I), en dA. Derecho Animal (Forum of Animal Law Studies) 8/2 (2017) 1ss. https://doi.org/10.5565/rev/da.318

${ }^{25}$ GIMÉNEZ-CANDELA, M., La Descosificación de los animales (I) (cit.) 1ss.; La Descosificación de los animales (II), en dA. Derecho Animal (Forum of Animal Law Studies) 8/3 (2017) https://doi.org/10.5565/rev/da.250 ; Descosificación de los animales en el Código civil español, en dA. Derecho Animal (Forum of Animal Law Studies) 9/3 (2018) https://doi.org/10.5565/rev/da.361 ;

${ }^{26}$ HEUMANN, H., SECKEL, E., Handlexikon zu den Quellen des römischen Rechts (11 a ed. Graz 1971) s.v. anima y animal

${ }^{27}$ BECK, A., The Biology of the Human Animal Bond, en Animal Frontiers 4/3 (2014) DOI:10.2527/af.2014-0019

${ }^{28}$ Un paso adelante en la afirmación de la consciencia de los animales, sin distinción de especies, significa The Cambridge Declaration on Consciousness, publicada el 7 de julio de 2012, firmada por un grupo de eminentes neurocientíficos (Philip Low, Jaak Panksepp, Diana Reiss, David Edelman, Bruno Van Swinderen, Christof Koch), propone en su párrafo final: "The absence of a neocortex does not appear to preclude an organism from experiencing affective states. Convergent evidence indicates that non-human animals have then euroanatomical, neurochemical, and neurophysiological substrates of conscious states along with the capacity to exhibit intentional behaviors. Consequently, the weight of evidence indicates that humans are not unique in possessing the neurological substrates that generate consciousness. Nonhuman animals, including all mammals and birds, and many other creatures, including octopuses, also possess these neurological substrates." CambridgeDeclarationOnConsciousness.pdf http://fcmconference.org/

${ }^{29}$ Vid. sumariamente, DE FONTENAY, E. Le silence des bêtes (Paris 1998); GUICHET, J.L., Rousseau, L'animal et l'homme. L'animalité dans l'horizon anthropologique des Lumières (Paris 2006).

BOUDOU, B., Montaigne et les animaux (Paris 2016); GONTIER, T., Intelligence et vertus animales: Montaigne lecteur de la zoologie antique, en Rursus 2 (2017) 5ss

${ }^{30}$ POLLO, Manifesto per un animalismo democratico (Roma 2021) $15 \mathrm{ss}$.

${ }^{31}$ BENTHAM, J., (London, 1748-1832), se considera el primer defensor del Bienestar Animal (“Animal Welfare”), en su obra, An Introduction to the Principles of Moral and Legislation, publicada en Londres en 1789 (año en que estalla la Revolución Francesa) y cuya última edición en inglés data de 2005 (Adamant Media Corporation), razonaba en los términos siguientes: que la capacidad de sufrir de los animales, más que su capacidad de hablar o razonar, era lo que les hacía merecedores de consideración y respeto: "What else is it that should trace the insuperable line? Is it the faculty of reason or perhaps the faculty of discourse? But a full-grown horse 


\section{y Darwin ${ }^{32}$.}

En los textos jurídicos no hay una delimitación de qué se entiende por animal, que tenga validez general. El Derecho no se ocupa de definir qué es animal al que se refieren las normas, cuando éstas tratan del bienestar o de la protección animal. Lo más frecuente en las últimas décadas, es que se sobreentienda que animal, en sentido jurídico es "el ser vivo dotado de sensibilidad" -para diferenciarlo de otras especies vivas- y que cada norma delimite qué es el animal al que se refiere o trata dicha norma ${ }^{33}$, de acuerdo con una clasificación basada en el uso o trato que se le da en dicha norma al animal ${ }^{34}$.

La denominación más general sobre animal, referida al ámbito Administrativo, Civil y Penal, se encuentra en el Diccionario Panhispánico del Español Jurídico ${ }^{35}$, que parece obsoleta en relación a los conocimientos científicos más recientes, pues pone el acento en la irracionalidad del animal, como signo distintivo de éste, pues entiende por animal, de forma singular:

\section{"Ser vivo irracional que siente y se mueve por sí mismo"}

Que esta definición está claramente desfasada, puede afirmarse en razón de que la racionalidad, como presupuesto de la "humanidad" del ser humano, para diferenciarlo de la "animalidad" de los animales, basada en la irracionalidad de los mismos ${ }^{36}$, es la clave de la distinción aristotélica entre el ser humano y el animal y la clave por ende para afirmar la superioridad del hombre sobre el animal ${ }^{37}$.

Por tanto, concurren dos argumentos o corrientes de pensamiento, que el legislador ha tenido en cuenta para regular, a lo largo del tiempo, el tratamiento de los animales:

a. Por un lado, el enfoque tradicional al que ya hemos hecho referencia, que basa la diferencia entre el hombre y el animal en la afirmación de la ausencia (en el animal) de capacidades que se predican como exclusivas del ser humano (racionalidad, habla). Este enfoque es el que ha permitido la cosificación de los animales, es decir, el tratamiento de los mismos como meras cosas en propiedad y lo que, potencialmente, habría podido justificar un trato jurídico del animal marginal y silenciado hasta extremos, que, si bien no asimilan indefectiblemente a los animales a las cosas inertes, abre sin embargo la puerta a un tratamiento jurídico exento de consideraciones de protección específica respecto al animal y, en último extremo, a un tratamiento laxo en relación al maltrato animal.

b. Por otro lado, el enfoque dominante a día de hoy, basado en el desarrollo de las ciencias de la biología y el bienestar animal, que pone de relieve la sentiencia ${ }^{38}$ como punto de encuentro entre hombre y animal. Con base en la afirmación de la importancia de la sentiencia, los animales no pueden ser tratados como meras cosas, sino de acuerdo con las exigencias que demanda su naturaleza de seres sentientes.

La sentiencia, puede afirmarse que es el argumento estrella hoy en día y la clave para entender el

or dog is beyond comparison a more rational, as well as more conversable animal, than an infant of a day or a week or even a month old. But suppose they were otherwise, what would it avail? The question is not, Can they reason?, nor Can they talk? but, Can they suffer? Why should the law refuse its protection to any sensitive being? The time will come when humanity will extend its mantle over everything which breathes".

${ }^{32}$ DARWIN, C., On the Origin of Species ( $1^{\text {a }}$ ed. London 1859)

${ }^{33}$ Una muestra, puede verse, por ejemplo, en el Reglamento (CE) n ${ }^{0} 1 / 2005$ del Consejo, de 22 de diciembre de 2004, relativo a la protección de los animales durante el transporte y las operaciones conexas, establece que, a efectos de este Reglamento, se entiende por "animales" los "animales vertebrados vivos" (artículo 2). Otro ejemplo: según el Convenio Europeo sobre la Protección de los Animales en las Explotaciones Ganaderas (10 de marzo de 1976), se entiende por "animales" los que se crían o mantienen para la producción de alimentos, lana, pieles, peletería u otros fines agrícolas (...)" (Art. 1)

${ }^{34}$ Esto ocurre, p.e., en la ley 32/2007 que añade un glosario de qué animales entran o no en la norma: Ley 32/2007, de 7 de noviembre para el cuidado de los animales, en su explotación, transporte, experimentación y sacrificio.

${ }^{35}$ Vid. Diccionario Panhispánico del Español Jurídico, publicado por la RAE, la Cumbre Judicial Iberoamericana y la Asociación de Academias de la Lengua Española (ed. 2020 https://dpej.rae.es/lema/animal). En dicho Diccionario, además de esta definición de animal, se hace un elenco de los siguientes 15 tipos de animales: amansado, asilvestrado, bravío, cuya carne o consumo se destine al consumo humano, de abasto, de compañía, de peletería, de producción, domesticado, doméstico, fiero, manso, peligroso, salvaje o silvestre y animales vivos.

${ }^{36}$ Vid. sobre el binomio animalidad-humanidad en el marco jurídico, PETERS, A., Liberté, Egalité, Animalité, en Transnational Environmental Law 5/1 (2016) 25ss. DOI: https://doi.org/10.1017/S204710251500031X; BURGAT, F., (dir.), L'animal dans nos sociétés, La documentation Française, coll. Problèmes économiques et sociaux (2004) 11 ss.

${ }^{37}$ Vid. desde la óptica de la biología, CHAPOUTHIER, G., KAPLAN, F., (cit.) 203-212.

38 PROCTOR, H., S., CARDER, G., CORNISH, A.R., Searching for Animal Sentience: A Systematic Review of the Scientific Literature, en Animals, 3/3 (2013) 882-906. DOI: https://doi.org/10.3390/ani3030882 ; JONES, R.C., Science, sentience, and animal welfare. Biology and Philosophy (2013), 1-30 DOI 10.1007/s10539-012-9351-1; PROCTOR, H., Animal Sentience: Where Are We and Where Are We Heading? en Animals 2/4 (2012) 628-639 DOI: https://doi.org/10.3390/ani2040628 
fenómeno de la descosificación animal en las legislaciones contemporáneas ${ }^{39}$. La sentiencia, en definitiva, se ha erigido como el anclaje principal, que ha permitido y permite al legislador introducir cambios para dotar a los animales de una mejora de su condición jurídica, cuya necesidad, dependiendo de los países, se argumenta como "modernización" "40, "modificación"41, o "adaptación"42. En realidad, que en el derecho positivo el animal se considere un "ser sentiente", es el argumento definitivo que permite al legislador proteger al animal.

El binomio sentiencia-protección animal, que aparece como una constante en los últimos años, está justificando la revisión de la normativa en nuestros Códigos y en la legislación sectorial de bienestar animal ${ }^{43}$. Pero así mismo, aunque no se haya profundizado mucho en el significado de sentiencia, el invocarla permite al legislador hacer una extensión novedosa que supere las barreras del animal-cosa. Este es el caso de las Constituciones de la Ciudad de México ${ }^{44}$, Ecuador ${ }^{45}$ y Brasil ${ }^{46}$ donde el animal sentiente, se integra como parte de una madre-naturaleza que provee la vida y que debe ser preservado y protegido. Es decir, se usa la sentiencia como argumento para la protección constitucional de la biodiversidad. Así mismo, la invocación de la sentiencia animal, está detrás de algunas decisiones de los tribunales, que se ven así respaldados para fallar en favor de los animales, por encima de su valor material como cosas en propiedad ${ }^{47}$, o para establecer, en el ámbito penal, la aplicación de las penas en su mayor cuantía ${ }^{48}$.

La sentiencia viene a ser un recurso universal, invocado para mejorar la protección animal o, incluso para justificarla. Es, por lo demás, un elemento fácil de reconocer a nivel social y ha servido y sirve como argumento para concienciar a la sociedad de que los animales "son como nosotros" y hay que "tratarlos, por lo menos, como a nosotros"49. Incluso esta simplificación de la sentiencia, parece estar detrás de las afirmaciones rotundas de que los "animales-no-son-cosas". En el fondo, un hermanamiento hombre-animal, que, aunque no desarrolle muy bien qué implicaciones tiene, se acepta y se difunde con gran facilidad. Una suerte de animalismo democrático ${ }^{50}$, que fluye con facilidad hoy en día e impulsa felizmente los movimientos sociales en apoyo de los cambios jurídicos en favor de los animales.

Sin embargo, a pesar de la popularidad del argumento de la protección animal basado en la sentiencia, subyace la dificultad de que por ser sentiente ("sentient being") se siguen entendiendo sólo los mamíferos, aves, reptiles, anfibios y, últimamente a reclamo de los científicos, también se han incluido los peces, los cefalópodos y los moluscos ${ }^{51}$.

Es claro que hay muchas especies animales que, para el Derecho, no entran dentro de ese paraguas protector de la sentiencia y si lo hacen parece establecerse una división entre algunos animales más sentientes que otros. Me refiero en concreto a los insectos, que con gran dificultad ven sus individualidades protegidas. Piénsese por ejemplo en el uso indiscriminado de herbicidas y venenos que están destruyendo de forma masiva a las mariposas, a las abejas ${ }^{52}$, a los caracoles ${ }^{53} \mathrm{y}$ a muchas especies que cumplen un papel muy relevante para

\footnotetext{
${ }^{39}$ Vid. supra n. 15.

${ }^{40}$ Francia: https://www.assemblee-nationale.fr/14/amendements/1808/AN/59.asp

${ }^{41}$ España: https://www.congreso.es/public_oficiales/L14/CONG/BOCG/B/BOCG-14-B-157-1.PDF\#page=1

${ }^{42}$ Austria: https://rdb.manz.at/document/ris.c.BGBL_OS_19880331_0_0179++; Alemania:

https:/www.bgbl.de/xaver/bgbl/start.xav?startbk=Bundesanzeiger_BGBBi\&umpTo=bgbl190s1762.pdf\#_bgbl_\%2F\%2F*05B\%4 0attr_id\%3D\%27bgbl190s1762.pdf\%27\%5D_ 1624985557468;

Suizä: https://www.fedlex.admin.ch/eli/fga/2002/895/de

${ }^{43}$ GIMÉNEZ-CANDELA, M., Transición animal en España (cit.) 168-171, 186-191, 201-203, 213-222.

${ }^{44}$ La Constitución de la Ciudad de México dentro del artículo 13 que se refiere a Ciudad Habitable, apartado B, señala lo siguiente: B. Protección n a los animales 1. "Esta Constitución reconoce a los animales como seres sentientes y, por lo tanto, deben recibir trato digno": http://www.cdmx.gob.mx/constitucion

${ }^{45}$ Art. 71 Constitución de la República del Ecuador:

https://www.defensa.gob.ec/wp-content/uploads/downloads/2021/02/Constitucion-de-la-Republica-del-Ecuador_act_ene-2021.pdf

${ }^{46}$ Art. 225 Constituição da Republica Federativa do Brasil: https://legis.senado.leg.br/norma/579494/publicacao/16434817

${ }^{47}$ El reconocimiento del daño moral por la muerte o lesiones del animal, en acto veterinario, o por el ataque de otro animal, en contra de la determinación del daño conforme al valor de mercado del animal.

${ }^{48}$ CUERDA ARNAU, ML (dir.), PERIAGO MORANT, JJ (coord.), De animales y normas. Protección animal y derecho sancionador (Valencia 2021); OLMEDO DE LA CALLE, E., Los delitos de maltrato animal en España (Valencia 2021).

49 BERTUZZI, N., I movimenti animalisti in Italia. Strategie, politiche e pratiche di attivismo (Milano 2018); 54ss.; 123ss.; GUAZZALOCA, G., Primo: non maltrattare. Storia della protezione degli animali in Italia (Bari-Roma 2018) 34ss.; 54ss.; 165ss.

${ }^{50}$ POLLO, S. Manifesto (cit.) 49ss.

${ }^{51}$ Así lo propugna la Declaración de Cambridge (vid. supra n. 28). Vid. por lo demás, en referencia a peces, GIMÉNEZ-CANDELA, M., M., SARAIVA, J.L., BAUER, H., The legal protection of farmed fish in Europe - analysing the range of EU legislation and the impact of international animal welfare standards for the fishes in European aquaculture, dA. Derecho Animal (Forum of Animal Law Studies) 11/1 (2020); GIMÉNEZ-CANDELA, M., Tratamiento jurídico de los peces en la UE y en España, dA. Derecho Animal (Forum of Animal Law Studies) 10/4 (2019).

${ }^{2}$ GIMÉNEZ-CANDELA, M., Abejas y Covid-19: una regulación jurídica necesaria, dA. Derecho Animal (Forum of Animal Law Studies) 11/4 (2020) 9-19. https://doi.org/10.5565/rev/da.558; GÓMEZ MALDONADO, L.D., Abejas y otros insectos polinizadores frente al uso indiscriminado de Neonicotinoides y Fipronil en Colombia. Comentarios a la sentencia del 12 de diciembre de 2019 del Tribunal Administrativo de Cundinamarca, dA. Derecho Animal (Forum of Animal Law Studies) 12/2 (2021).
}

${ }^{53}$ GIMÉNEZ-CANDELA, M., Transición animal en España (cit) 39-42. 
la conservación de la biodiversidad. La normativa aplicable a estos pequeños -pero importantes- seres vivos y sentientes es muy escasa en comparación con la destinada a animales de compañía o de producción, aunque su importancia económica sea tan grande o al menos parangonable a la de las vacas, ovejas o cerdos, si es que la clasificación de los animales en razón de su valor económico es lo que los hace más merecedores de ser protegidos. Sin temor a exagerar, puede decirse que, al menos hasta ahora, la atención que la legislación les ha prestado ha sido muy escasa y de carácter secundario.

Conviene pues llamar la atención sobre el hecho de que, cuando nuestro Código civil se refiere a los animales como cosas en propiedad, sólo está haciendo referencia a los llamados animales domésticos. Ahí no entran todos los animales, sino sólo aquellos a los que el antecedente romano del Código Napoleón hacía referencia ${ }^{54}$. Es decir, los animales que contribuían al sostenimiento de la economía familiar y rural: los animales de tiro y carga y los animales que proveían de sustento a la familia, para el alimento, la guarda, o para el pequeño comercio. Doméstico significa que vive en y para la casa (domus). Razón por la cual, el punto distintivo de la categoría es tan flexible como difícil de determinar. La distinción entre animal doméstico y silvestre estriba en la afirmación de que el doméstico conserva el instinto de volver a su lugar de procedencia (al corral, al cercado, a la casa), lo que se conoce con el nombre de animus revertendi ${ }^{55}$. A día de hoy, por muy lejana que nos parezca la invocación de este elemento cotidiano, que parte de la observación más directa del comportamiento animal, sigue sin embargo estando presente para determinar si el animal está o no incluido en la categoría de animal considerado como cosa por el Código civil.

Difusa, inexacta y obsoleta o no, la verdad es que la categoría de animal doméstico es la que el Código regula en todos sus apartados y artículos. Sobre este punto no hay discusión. Es claro que, si los animales de los que habla el Código son los domésticos, la regulación de todos los demás animales (que no son pocos) queda a expensas de otras disposiciones que, se han ido incorporando de manera progresiva en el corpus de nuestra legislación. En concreto, en la legislación española, la atención prioritaria a los animales ha venido de la mano de la muy abundante legislación europea sobre bienestar animal, tanto a nivel estatal como autonómico ${ }^{56}$, como no podía ser de otro modo, dada la condición de España como estado miembro de la UE.

\section{Las claves de la propuesta de modificación del Código civil. Descosificación}

La propuesta de modificación del Código civil está actualmente en fase de tramitación ${ }^{57}$, tras haberse interrumpido abruptamente por las conocidas circunstancias políticas. De todo ello me ocupé de forma muy detallada en 2019 en un artículo publicado en esta misma sede ${ }^{58}$. Me permito transcribir una reflexión personal publicada entonces, que ha venido a ser premonitoria:

"Que la reforma del estatuto jurídico de los animales en el Código civil no haya culminado con su aprobación, es en mi opinión, una etapa más de un recorrido que será difícil que no se retome con el nuevo Parlamento surgido de las urnas el 28 de abril de 2018. Los elementos que la propiciaron siguen vigentes. La sociedad ha cambiado su actitud respecto a los animales, la ciencia cada vez ofrece resultados más consolidados en afirmación de la sentiencia animal, el movimiento descosificador es una realidad global perceptible en muchos países y, por último, la legislación del Bienestar animal sigue vigente y vincula a España como estado Miembro que no puede desoír sus obligaciones".

Sumariamente, las claves que sustentaron la propuesta de reforma del $2017^{59}$, han vuelto a impulsar esta propuesta, de forma casi inalterada y persistente en la voluntad de dotar de un nuevo estatuto jurídico a

\footnotetext{
${ }^{54}$ GIMÉNEZ-CANDELA, T., Derecho privado romano (cit.) 168.

55 Sobre animus revertendi, del que, al parecer, las gallinas romanas carecían, o al menos los juristas romanos discutían arduamente sobre si podían ser domésticas porque no parecían volver si se iban del corral, vid. GIMÉNEZ-CANDELA, T., Derecho privado romano (cit.) 169, 189.

${ }^{56}$ VILLALBA, T., Código de Protección y Bienestar Animal (BOE 2021):

https://www.boe.es/biblioteca_juridica/codigos/codigo.php?id=204_Codigo_de_Proteccion_y_Bienestar_Animal\&modo=2

${ }^{57}$ El Pleno de los Diputados ha aprobado en la sesión de 20 de abril de $202 \overline{1}$, la toma en consideración de la Proposición de Ley de modificación del Código Civil, la Ley Hipotecaria y la Ley de Enjuiciamiento Civil, sobre el régimen jurídico de los animales, presentada por el Grupo Parlamentario Socialista, publicada en el «BOCG. Congreso de los Diputados», serie B, núm. 157-1, de 26 de marzo de 2021. https://www.congreso.es/public_oficiales/L14/CONG/BOCG/B/BOCG-14-B-157-1.PDF\#page=1

58 GIMÉNEZ-CANDELA, M., Animales en el Código civil español: una reforma interrumpida, dA. Derecho Animal (Forum of Animal Law Studies) 10/2 (2019) 7-12. DOI https://doi.org/10.5565/rev/da.438

${ }^{59}$ Diario de Sesiones del Congreso de los Diputados, pleno y diputación permanente, Año 2017, № 29, XII Legislatura, sesión plenaria $\mathrm{N}^{\circ}$ 27, martes, 14 de febrero de 2017, págs. 43-50. http://www.congreso.es/public_oficiales/L12/CONG/DS/PL/DSCD-12-PL29.PDF; BOGC de 13 de Octubre de 2017 (122/00034) Proposición de Ley de modificación del Código Civil, la Ley Hipotecaria y la Ley de Enjuiciamiento Civil sobre el régimen jurídico de los animales.

http://www.congreso.es/public_oficiales/L12/CONG/BOCG/B/BOCG-12-B-167-1.PDF\#page=1
} 
los animales, considerados como seres sentientes, o sensibles, como también se indica ${ }^{60}$. Me refiero a los cuatro ejes temáticos que detallo a continuación:

a. El cambio de sensibilidad social hacia los animales

b. Los avances científicos, cada vez más difundidos, que afirman la sentiencia animal

c. El movimiento descosificador de carácter global

d. La legislación de Bienestar animal que tiene carácter vinculante para España, como Estado Miembro de la UE

La Proposición de ley de modificación del Código civil, la Ley Hipotecaria y la Ley de Enjuiciamiento civil se hace eco de forma exacta de dichos aspectos para crear lo que quizá podría llamarse un nuevo régimen civil destinado a los animales ${ }^{61}$. El texto cuya tramitación se ha aprobado ahora, recoge con algunas diferencias la propuesta fallida, que, en su momento fue votada unánimemente por dos veces en el Parlamento ${ }^{62}$, lo que, en esta ocasión no ha sido así, pues ha sido respaldada por una mayoría de los parlamentarios con algunas severas discrepancias ${ }^{63}$. No obstante, el mencionado proyecto de modificación del estatuto jurídico de los animales en el Código civil, con las diferencias respecto a la propuesta anterior, sigue su curso. Habrá que ver -si se aprueba definitivamente-, cómo queda el texto final. Todo lo que aquí se puede decir, está, como no puede ser de otro modo, sometido en estos momentos a la tramitación de las enmiendas que pueden alterar formal y sustancialmente el texto.

Con arreglo a los referidos ejes temáticos, voy a ir desgranado algunas de las claves de entendimiento de la nueva propuesta. Me referiré de nuevo a la modificación del Código civil en tramitación -que ya propuse en 2009-, aún a contracorriente para la mentalidad de los juristas de la época, como eje vertebrador del cambio de tratamiento que se debía reconocer a los animales ${ }^{64}$. La referencia, en esta ocasión será deliberadamente breve, en espera del texto definitivo, pues en los trabajos que he publicado hasta el presente ${ }^{65}$, se hace una reflexión mucho mas detallada, amplia y completa del marco general de referencia, que es el aspecto central a tratar ahora: el cambio de estatuto jurídico de los animales en el Código civil.

a) El cambio de sensibilidad social hacia los animales. Que la sociedad ha cambiado su percepción acerca del trato que corresponde dar a los animales, se advierte en la modificación de algunos hábitos sociales en los últimos diez años tanto en el ámbito cultural, como en el rechazo al maltrato animal ${ }^{66}$. Esta tendencia, se ha plasmado recientemente en la inclusión obligatoria de la "educación en la empatía hacia los animales", que figura en la Ley de Educación aprobada por el Parlamento en diciembre de 2020, que establece entre los principios generales del sistema educativo: "i) Conocer y valorar los animales más próximos al ser humano y adoptar modos de comportamiento que favorezcan la empatía y su cuidado"67. No ha habido posteriores concreciones acerca de qué se entiende por "animales más próximos al ser humano", ni si dicha proximidad se refiere al ámbito físico (animales de compañía) o biológico (mamíferos), pero, en todo caso, cabe destacar que es la primera vez que "educar en los valores de empatía hacia los animales", figura entre los objetivos del

\footnotetext{
${ }^{60}$ DE TORRES PEREA, JM., El nuevo estatuto jurídico de los animales en el Derecho civil: de su cosificación a su reconocimiento como seres sensibles (Madrid 2020); rec. de CERDEIRA BRAVO DE MANSILLA, Entre personas y cosas: los animales, ¿como tertium genus?, en Revista de Derecho Privado, 3 (2020) 113-128.

${ }^{61}$ Vid. en este mismo volumen de la revista, el editorial invitado de CERDEIRA BRAVO DE MANSILLA, G., ¿Un nuevo Derecho civil para los animales?: Elogio (no exento de enmiendas) a la nueva Proposición de Ley sobre el régimen jurídico de los animales en España, en dA. Derecho Animal (Forum of Animal Law Studies) 12/2 (2021).

62 Vid. supra n. 59.

${ }^{63}$ Diario de Sesiones del Congreso de los Diputados, pleno y diputación permanente, Año 2021, No 96, XIV Legislatura, sesión plenaria $\mathrm{N}^{\circ}$ 92, martes, 20 de abril de 2021, págs. 17-33. https://www.congreso.es/public_oficiales/L14/CONG/DS/PL/DSCD-14-PL96.PDF\#page $=26$

${ }^{64}$ Dos Proyectos de investigación sucesivos, concedidos por el MINECO, dan cumplida cuenta de esta trayectoria. Me refiero a los Proyectos titulados: "Estatuto jurídico de los animales: orígenes, dificultades y nuevas expectativas en un mundo globalizado". Ministerio de Economía y Competividad (MINECO DER2010-21301-1) 2011-2013 y "Estatuto jurídico de los animales: orígenes, dificultades y nuevas expectativas en un mundo globalizado". Ministerio de Economía y Competividad (MINECO DER2015-69314P) 2015-2019. De los trabajos publicados da cuenta el informe, "El ICALP a favor de la descosificación jurídica de los animales" (Junio 2021) https://www.derechoanimal.info/es/icalp/actividades/2021/el-icalp-favor-de-la-descosificacion-juridica-de-losanimales

${ }^{65}$ GIMÉNEZ-CANDELA, T., La Descosificación de los animales (I) y II (cit.) 1ss.; La Descosificación de los animales en el Cc. Español (cit.) 7-47; Animales en el Código civil español: una reforma interrumpida, en dA. Derecho Animal (Forum of Animal Law Studies) 10/2 (2019) 7-18. https://doi.org/10.5565/rev/da.438

${ }^{66}$ GIMÉNEZ-CANDELA, M., Transición animal (cit.) 35ss.; 83ss.

${ }^{67}$ Modificación del apartado i) del art. 17. Ley Orgánica 3/2020 por la que se modifica la Ley Orgánica 2/2006, de 3 de mayo, de Educación, BOE n³40, de 30 de diciembre de 2020 https://www.boe.es/eli/es/lo/2020/12/29/3

14 Derecho Animal. Forum of Animal Law Studies, vol. 12/2
} 
sistema educativo español. Más allá del clima de opinión favorable a un cambio de estatuto jurídico de los animales por parte de la ciudadanía, lo que el texto actualmente en trámite ofrece es el establecimiento de algunos cambios jurídicos que merecen destacarse, independientemente de si vayan a permanecer o no en el texto definitivo. Detallo sólo algunos aspectos como ya he advertido.

b) Los avances científicos, cada vez más difundidos, que afirman la sentiencia animal. Los animales aparecen como una categoría separada en el título de propiedad, lo que evidencia que no se trata sólo de dotar de algunas mejoras al tratamiento civil de los animales, sino de reconocerles una individualidad separada de los bienes, lo que evita la confusión entre cosas sin más y animales. Aquí no se trata tanto de crear una nueva categoría referida a los animales (una suerte de "tertium genus"), sino de plasmar en el texto la diferencia natural entre cosas y animales. Lo que podríamos calificar de una categoría "sui generis", tal como aparece en muchos textos de los autores de la Antigüedad clásica.

Interesante resulta que, en la Exposición de motivos de la actual Proposición, no haya ningún cambio respecto a la Exposición de motivos de 2017 que, como la presente, constaba de tres párrafos. En el primero (I) se hace referencia al marco general europeo y comunitario cuyo espíritu inspira y justifica la propuesta, que no es otro que, dicho aquí en forma breve, la referencia obligada al movimiento de descosificación animal que se inició a finales de los años 80 en Austria, Alemania y Suiza ${ }^{68}$. En los referidos Códigos el cambio de estatuto jurídico de los animales, se hacía de forma negativa: los animales no son cosas ("Nicht Sachen"), formulación que repitió en su literalidad el Código civil catalán ${ }^{69}$, que se adelantó con ello a la actual Proposición de reforma del Código civil que sigue considerando a los animales como cosas muebles. Más adelante, en 2015, el Código civil francés, daría un importante paso adelante, sin duda por influencia de los avances de la ciencia del Bienestar Animal acerca de la sentiencia y de la inclusión de la sentiencia como principio mandatorio para todos los Estados Miembros de la UE, como refleja el art. 13 TFUE. En efecto, el Código Napoleón, siguió la impronta revolucionaria que lo auspició ${ }^{70}$ y -también en tema de estatuto de los animales-, se apartó de la formulación negativa para afirmar que los animales son "...êtres vivants doués de sensibilité". ${ }^{71}$ A partir de ahí, los restantes Códigos europeos y latinoamericanos que han modificado el estatuto jurídico de los animales, lo han hecho conforme a la afirmación de la sentiencia de los mismos. Me refiero, por ejemplo, a los Códigos de Portugal, Liechstenstein y Chequia y al Código civil de Colombia.

En el segundo párrafo (II) se expone que la reforma se inspira en un "criterio protector" respecto de los animales, en consonancia con el cual debe establecerse que los animales, aún estando sujetos al régimen de la propiedad, tienen una naturaleza distinta a la de las cosas o bienes y se fija dicha afirmación como "principio que ha de presidir la interpretación de todo el ordenamiento", lo que es, hay que reconocerlo, un ambicioso propósito y una singularidad que ya ha llamado la atención de insignes juristas ${ }^{72}$. En dicho sentido se establece la reforma del art. 333 del CC que pasa a tener el siguiente tenor ${ }^{73}$ :

“1. Los animales son seres vivos dotados de sensibilidad. Solo les será aplicable el régimen jurídico de los bienes y de las cosas en la medida en que sea compatible con su naturaleza y con las disposiciones destinadas a su protección.

2. El propietario, poseedor o titular de cualquier otro derecho sobre un animal debe ejercer sus derechos sobre él y sus deberes de cuidado respetando su cualidad de ser vivo dotado de sensibilidad, asegurando su bienestar conforme a las características de cada especie y respetando las limitaciones establecidas en ésta y las demás normas vigentes.

3. Los gastos destinados a la curación y al cuidado de un animal herido o abandonado por un tercero son recuperables por quien los haya pagado en la medida en que hayan sido proporcionados y aun cuando hayan sido superiores al valor del animal.

\footnotetext{
${ }^{68}$ GIMÉNEZ-CANDELA, M., La Descosificación de los animales en el Cc. Español (cit.) 19ss.

${ }^{69}$ Art. 511-1.3 CCCat: "Los animales, que no se consideran cosas, están bajo la protección especial de las leyes. Solo se les aplican las reglas de los bienes en lo que permite su naturaleza". https://www.boe.es/eli/es-ct/1/2006/05/10/5/con

70 GIMÉNEZ-CANDELA, T., Una nueva Revolución Francesa: la modernización del Code civil, dA. Derecho Animal (Forum of Animal Law Studies) 6/1 (2015) 1-2. https://doi.org/10.5565/rev/da.270 ; LELANCHON, L., La reforma del estatuto jurídico civil de los animales en el Derecho francés, en dA. Derecho Animal (Forum of Animal Law Studies) 9/3 (2018) https://doi.org/10.5565/rev/da.344

${ }^{71}$ Tampoco en francés se admite el termino equivalente al inglés "sentience" o "sentient beings" por lo que el legislador tuvo que recurrir a un giro lingüístico para referirse a la realidad de que los animales no son cosas inertes. Pero, en realidad, sentiencia no expresa lo mismo que "sensibilidad" ni en francés ni en castellano, por lo que sería muy deseable que dichos términos fueran acogidos en breve por los respectivos diccionarios, en Francia y en España.

72 ROGEL VIDE, C., Personas, animales y Derechos (Madrid-México 2018); Los animales en el Código Civil (Madrid 2017); Personas, animales y androides, en RGLJ, 4 (2017) pp. 681-693
}

${ }^{73}$ Vid. supra n. 57 
4. En el caso de que la lesión a un animal de compañía haya provocado su muerte o un menoscabo grave de su salud física o psíquica, tanto su propietario como quienes convivan con el animal tienen derecho a que la indemnización comprenda la reparación del daño moral causado".

En el párrafo 1 y 2 de la nueva redacción del art. $333 \mathrm{CC}$, al igual que en otros Códigos europeos, se abre una dualidad de tratamiento de los animales: por un lado su condición de cosas en propiedad y por otra la restricción al tradicional principio de uso ilimitado o abuso (ius abutendi) del propietario en el uso y disfrute de la cosa objeto de su propiedad ${ }^{74}$, que incluso concede la posibilidad de destrucción de la misma (disposición material). Lo que se fija aquí, en el sentido más estricto, es un límite a las facultades inherentes a la propiedad que procede de imponer al propietario un uso de los animales que no vaya en contra de lo que la declarada naturaleza de "ser vivo y sensible" (ser sentiente-"sentient being") exige.

La redacción del $\S 903 \mathrm{BGB}^{75}$ reza en el mismo sentido. Transcribo aquí, con mi propia traducción del alemán, el citado parágrafo:

\section{$\S 903$ Befugnisse des Eigentümers}

Der Eigentümer einer Sache kann, soweit nicht das Gesetz oder Rechte Dritter entgegenstehen, mit der Sache nach Belieben verfahren und andere von jeder Einwirkung ausschließen. 2. Der Eigentümer eines Tieres hat bei der Ausübung seiner Befugnisse die besonderen Vorschriften zum Schutz der Tiere zu beachten.

\section{$\S 903$ Facultades del propietario}

El propietario de una cosa puede, salvo que la ley o los derechos de terceros se opongan a ello, tratar el objeto como le plazca y excluir a los demás de cualquier interferencia. 2.El propietario de un animal deberá, en el ejercicio de sus facultades, respetar las normas especiales de protección de los animales.

Como algunos respetados estudiosos han observado ${ }^{76}$, esta restricción del derecho de propiedad sobre los animales, está ligada desde 1990 a la aprobación de la descosificación animal, de acuerdo con el §90a $\mathrm{BGB},{ }^{77}$ al respeto a las normas específicas de protección animal, lo que constituye un reenvío a toda la legislación de bienestar animal, que en Alemania, como es sabido, tiene carácter de ley propia ${ }^{78}$.

Digna de destacar, sin duda, es la referencia al derecho de indemnización del propietario del animal por daños morales que aparece en el apartado 4 del redactado propuesto para el art. $333 \mathrm{CC}$. Nos encontramos aquí con una esperada regulación por parte del legislador, que oriente y dé soporte a las muchas sentencias que desde hace años se vienen dictando en este sentido ${ }^{79}$. De especial interés, en este sentido, es la recopilación y comentario de sentencias dictadas en Cataluña, anteriores a la Proposición de Modificación del régimen jurídico de los animales al que me refiero ${ }^{80}$.

a) El movimiento descosificador de carácter global.

En los escritos que he dedicado a la descosificación en los últimos años ${ }^{81}$, está ampliamente desarrollado y razonado este argumento, por lo que me remito a lo dicho. Sólo quiero en esta ocasión hacer algunas consideraciones sobre el ámbito global del movimiento de descosificación animal, que es en el que se inserta la Proposición de Modificación del régimen jurídico de los animales en

\footnotetext{
${ }^{74}$ Vid. una aplicación reciente por CERDEIRA BRAVO DE MANSILLA, Clínicas veterinarias y paseos con animales de compañía ante el COVID-19: una actividad esencial para el bienestar del animal como ser sintiente, dA. Derecho Animal (Forum of Animal Law Studies) 11/2 (2020). DOI https://doi.org/10.5565/rev/da.499

${ }^{75} \S 903$ BGB: http://www.gesetze-im-internet.de/bgb/_903.html

76 SCHERMAIER, M., Der zivilrechtliche Eigentumsbegriff in historischer Perspektive: Die beiden Gesichter des $\S 903$ BGB, en BRINKMANN, M., SHIRVANI, F., Privatrecht und Eigentumsrecht (Baden-Baden 2016), 23-62

$77 \$ 90^{\mathrm{a}}$ BGB: "Tiere sind keine Sachen. Sie werden durch besondere Gesetze geschützt. Auf sie sind die für Sachen geltenden Vorschriften entsprechend anzuwenden, soweit nicht etwas anderes bestimmt ist."/ "Los animales no son cosas. Están protegidos por leyes especiales. Las disposiciones aplicables a la propiedad se les aplicarán por igual, salvo disposición en contrario". http://www.gesetze-im-internet.de/bgb/_90a.html

78 Art. 23 GG: https://www.gesetze-im-internet.de/gg/art_23.html: Art. 25: https://www.gesetze-im-internet.de/gg/art_25.html; Art. $31 \mathrm{GG}$ : https://www.gesetze-im-internet.de/gg/art 31.html

${ }^{79}$ Vid. la primera sentencia dictada en España a favor del reconocimiento de daños morales por la muerte de un perro, dictada por el juez Guillermo Arias, a quien se debe el Comentario de la misma en una suerte de ejercicio de autocrítica altamente interesante. SJPI Barcelona 466/07 de 16 de mayo; ARIAS, G., Comentario critico sobre la Sentencia de las actuaciones que se siguieron en el Juzgado de Primera Instancia núm. 32 de Barcelona con el número de autos 466/07 (16.5.2007) en dA. Derecho Animal (Forum of Animal Law Studies) 1/1 (2010) 1ss. https://doi.org/10.5565/rev/da.236

${ }^{80}$ OLIVERA OLIVA, M., Crisis de pareja de hecho y animales de compañía. Sentencias en Cataluña, anteriores a la propuesta de reforma del Código Civil de 20 de abril de 2021, dA. Derecho Animal (Forum of Animal Law Studies) 12/2 (2021).

${ }^{81}$ Vid. supra n. 25

16 Derecho Animal. Forum of Animal Law Studies, vol. 12/2
} 
nuestro Código civil, tal como invoca la propia Exposición de motivos en su apartado segundo (II). La invocación de los Códigos continentales que han culminado dicha descosificación, inserta finalmente al legislador español en una corriente a la que no podía sustraerse, por la razón de que en el propio suelo patrio el Código civil catalán en el 2006 se unió a los Códigos austríaco, alemán y suizo al declarar a los animales como no-cosas ${ }^{82}$.

También las leyes de protección animal que las Comunidades Autónomas han promulgado, en uso de las competencias en la materia de bienestar animal concedidas por la Constitución ${ }^{83}$, constituyen un adelanto de la voluntad descosificadora del legislador. Baste mencionar la Ley 7/2020 de Bienestar, Protección y Defensa de los animales de Castilla la Mancha, que moderniza la Ley 7/1990 de 28 de Diciembre de Protección de los animales domésticos ${ }^{84}$ y puntualiza en su art. 2 la cualidad de "seres sentientes" y el especial deber por ello de protegerlos y salvaguardar su bienestar ${ }^{85}$. En otros términos, la descosificación de los animales ha venido de la mano de dos elementos principales, que son, la afirmación de la sentiencia por parte de la comunidad científica y la aplicación de dicho principio a la legislación de bienestar animal, a la que los Estados Miembros de la UE no pueden sustraerse (art. 13 TFUE).

En este sentido, por esta vía de aplicación de los principios de bienestar animal en la legislación, la globalización de la protección animal, que lleva aparejada la descosificación de los animales va más allá del ámbito europeo ${ }^{86}$, para alcanzar a países como China, como ponen de relieve los estudios más recientemente publicados ${ }^{87}$

b) La legislación de Bienestar animal que tiene carácter vinculante para España, como Estado Miembro de la UE.

La Exposición de motivos invoca la pretensión protectora que preside la Modificación del CC en curso, tomando ocasión de la aplicación en España de la legislación europea de Bienestar Animal que tiene carácter mandatorio. Hay que llamar la atención sobre este aspecto, porque pone en relación directa el cambio de régimen jurídico de los animales, que sustancia la Proposición de Modificación del CC en trámite con todo un corpus de legislación europea referido básicamente a los animales de producción. Lo que, con cierta ironía, se ha llamado el tratamiento de los animales como "productos o mercancías sentientes".

La observación que he realizado acerca de a qué animales se aplica el Código civil ${ }^{88} \mathrm{y}$, por tanto, a cúales se aplicaría el proyectado cambio de estatuto jurídico, encuentra aquí precisamente su confirmación y su principio de interpretación. El ámbito de aplicación de la reforma en curso, está vinculada al sentido en el que se pronuncia el art. 13 TFUE, que restringe la protección de los animales como seres sentientes ("sentient beings") a ciertas actividades taxativamente enumeradas en el primer párrafo (agricultura, pesca, transporte, mercado interior, investigación y desarrollo tecnológico), mientras que en el segundo, excluye ciertas actividades y, por ello, a ciertos animales, de dicha protección basada en la sentiencia (las disposiciones legales o administrativas y las costumbres de los Estados Miembros relativas, en particular, a ritos religiosos, tradiciones culturales y patrimonio regional). La puerta que abre ese segundo párrafo del art. 13 TFUE, está plagado de incógnitas y de interrogantes muy arduos, pues establece dos categorías de animales sentientes: los que están protegidos de forma mandatoria en la UE en razón de las actividades de carácter fundamentalmente industrial y económico en las que están envueltos y los que no lo están, pues su protección está subordinada al respeto por un elenco de actividades en las que prima, como criterio superior, el respeto por las tradiciones y la cultura ${ }^{89}$.

El Código trata en principio de los animales domésticos lo que incluye a los de producción y los de compañía, pero surgen las dudas acerca de si, con la modificación del régimen jurídico que se está tramitando, también vendrían a estar protegidos como "seres sentientes" los peces, moluscos y

\footnotetext{
${ }^{82}$ Vid. supra n. 15

${ }^{83}$ Art. 148 CE: https://www.boe.es/buscar/act.php?id=BOE-A-1978-31229

${ }^{84}$ Comunidad Autónoma de Castilla-La Mancha «DOCM» núm. 1, de 2 de enero de 1991 «BOE» núm. 93 , de 18 de abril de 1991 Referencia: BOE-A-1991-9406: https://www.boe.es/buscar/pdf/1991/BOE-A-1991-9406-consolidado.pdf

${ }^{85}$ Vid. GISIE, L., Comentario jurídico de la Ley 7/2020, de 31 de agosto, de Bienestar, Protección y Defensa de los Animales de Castilla-La Mancha. [2020/6154] - Diario Oficial de Castilla-La Mancha de 07-09-2020, en dA. Derecho Animal (Forum of Animal Law Studies) 12/1 (2021). DOI https://doi.org/10.5565/rev/da.556

${ }^{86}$ PETERS, A., Animals in International Law. Hague Academy of International Law. Offprint from the Recueil des cours, 140 (LeidenBoston 2020) 345ss., vid. la edición de bolsillo aparecida en 2021, Animals in International Law, The Pocket Books of The Hague Academy of International Law / Les livres de poche de l'Académie de droit international de La Haye, 45 (Leiden-Boston) 2021.

${ }^{87}$ LI, P., Animal Welfare in China (Sidney University Press 2021)

${ }^{88}$ Vid. supra sub.I.

${ }^{89}$ GIMÉNEZ-CANDELA, M., Transición animal en España (cit.) 35ss., 83-105.
} 
cefalópodos de piscifactoría ${ }^{90}$, y las abejas de las explotaciones apícolas ${ }^{91}$, pues son actividades que podrían encuadrarse en el primer párrafo del art. 13 TFUE.

Quedan otros aspectos a los que ahora y aquí no voy a hacer referencia. Son los aspectos mas tradicionalmente ligados al carácter rural del Código civil en relación con los animales, como es todo lo referido a los frutos, los inmuebles por destinación. Me parece preferible, conociendo desde dentro la propuesta de reforma, dejar el comentario para el momento en que ésta se consolide en un texto aprobado.

En definitiva y como resumen de lo que vengo comentando, sustancio en los siguientes siete puntos los aspectos clave de la Proposición de Modificación del régimen jurídico de los animales en el CC: ${ }^{92}$

1. No es una modificación "nominalista" (mero cambio o inclusión de un nombre o una referencia: sentiencia, sino que tiene vertiente y efecto procesal: LEC y Ley Hipotecaria)

2. Inembargabilidad

3. Tenencia compartida de los animales domésticos

4. Animales como seres sentientes, conexión con art. 13 TFUE y la legislación española de Bienestar Animal

5. La cuestión de los frutos

6. La cuestión de los inmuebles por destinación

7. La penalidad del maltrato animal, incluida en el CC

\section{Los posibles efectos de la modificación en curso}

Dos de las novedades de la proyectada modificación del régimen jurídico de los animales, que más han llamado la atención tanto de los estudiosos como de la sociedad, han sido el de la declaración de exclusión del embargo sobre los animales ${ }^{93}$ y el de la facultad para los jueces de la atribuir la tenencia compartida de los animales de compañía, en casos de crisis matrimoniales y de pareja ${ }^{94}$. Sobre ambos aspectos, dejo a la posible revisión y comentario del texto en trámite que éste se apruebe y sepamos realmente cúal será el texto consolidado. Por ahora, sólo quiero obhservar que, tanto la inembargabilidad de los animales como el papel que se atribuye al juez de poder confiar la tenencia compartida del animal de compañía en los casos de crisis familiares, el presupuesto es la relación o vínculo de afecto entre el animal y el ser humano. Que dicha especial relación de afecto encuentre cabida en esta reforma, subraya la coherencia de la misma con el espectro con el que han regulado esta cuestión los Códigos centroeuropeos (Austria, Suiza y Alemania) a lo que en otro momento dediqué mi atención y a lo que me remito ${ }^{95}$.

Las posibles extensiones de lege ferenda que podrían anunciarse de forma cautelar, si la modificación del régimen jurídico de los animales culmina con éxito, pueden concretarse de forma muy sintética en los siguientes puntos:

1. Sentencias, nuevo ámbito para la magistratura

2. Nueva regulación del ámbito procesal (LEC) y de la Ley Hipotecaria

3. Cambios en la estructura de la familia (vínculo de afecto)

4. Revisión de la legislación española de bienestar animal (peces, moluscos y cefalópodos, p.e.)

5. Revisión de la legislación de PPP

6. Revisión de la normativa de espectáculos públicos (ferias, festejos, tauromaquia)

7. Protección de los insectos (no considerados, ni protegidos, sino "gestionados)

8. Un Manifiesto Pro Derecho Animal:

a) El Derecho Animal como instrumento de convivencia democrática (Ciudadanía)

\footnotetext{
${ }^{90}$ GIMÉNEZ-CANDELA, M., M., SARAIVA, J.L., BAUER, H. (cit.) 65-119. https://doi.org/10.5565/rev/da.460

${ }^{91}$ Vid supra n. 52

${ }^{92}$ ERNIQUIN, T., Les animaux vivants et la libre circulation: un statut de merchandises sensibles, en Revue des Affaires Europeennes 24 (2017) 49ss.

${ }^{93}$ Vid. el estudio monográfico sobre esta cuestión de, FRUCTUOSO, I., Los animales y las medidas coercitivas de carácter procesal (Valencia 2021) en prensa.

${ }^{94}$ CERDEIRA BRAVO DE MANSILLA, G., Crisis familiares y animales domésticos (Madrid 2019); OLIVERA OLIVA, M., La tenencia compartida de un animal doméstico como ser sintiente. Comentario a la sentencia de fecha 27 de mayo de 2019 del Juzgado de Primera Instancia $n^{\circ} 9$ de Valladolid. Magistrado-juez: D. Luis C.Tejedor Muñoz, en dA. Derecho Animal (Forum of Animal Law Studies) 10/4 (2019) 155-158. https://doi.org/10.5565/rev/da.467; CASAS DÍAZ, L., CAMPS I VIDELLET, X., Las crisis matrimoniales y los animales de compañía: una aproximación práctica desde el ejercicio de la abogacía, en dA. Derecho Animal (Forum of Animal Law Studies) 10/1 (2019) 76-83. https://doi.org/10.5565/rev/da.397

95 Vid. supra n. 25

18 Derecho Animal. Forum of Animal Law Studies, vol. 12/2
} 
b) El Bienestar Animal como compromiso dentro del desarrollo sostenible (Estados/Estado/Policy)

c) El estudio del Derecho Animal como paradigma de cambio social (Academia)

i. Facultades de Derecho

ii. Facultades de Veterinaria

d) El Veganismo como replanteamiento de la relación humano-animal (nuevos espacios de convivencia)

e) El etiquetaje en la sociedad de la información como indicador de la transferencia academiaempresa

Agradecimientos. A mis Compañeros de la Redacción de la revista, Raffaela Cersosimo y Oliver Wookey, les debo un agradecimiento especial por su ayuda imprescindible. La revisión del texto, la puntualización crítica y el estímulo intelectual son el mejor ambiente que se puede desear para seguir escribiendo.

\section{Referencias}

\section{Fuentes}

- D. 28.2.12.1 (Ulp. 9 ad Sab.)

- D 50.16.124 (Proc. 2 epist.)

- Amendement n. 59 du 11 avril 2014 presente par M. Glavany et al. : https://www.assembleenationale.fr/14/amendements/1808/AN/59.asp

- Art. 148 CE: https://www.boe.es/buscar/act.php?id=BOE-A-1978-31229

- Art. 23 GG: https://www.gesetze-im-internet.de/gg/art_23.html

- Art. 25 GG: https://www.gesetze-im-internet.de/gg/art_25.html

- Art. $31 \mathrm{GG}$ : https://www.gesetze-im-internet.de/gg/art_31.html

- Art. 13 Constitución de la Ciudad de México: http://www.cdmx.gob.mx/constitucion

- Art. 71 Constitución de la República del Ecuador: https://www.defensa.gob.ec/wpcontent/uploads/downloads/2021/02/Constitucion-de-la-Republica-del-Ecuador_act_ene-2021.pdf

- Art. 225 Constituição da Republica Federativa do Brasil: https://legis.senado.leg.br/norma/579494/publicacao/16434817

- \$285a ABGB: https://www.ris.bka.gv.at/eli/jgs/1811/946/P285a/NOR12018011

- $\$ 90^{\mathrm{a}}$ BGB: http://www.gesetze-im-internet.de/bgb/ 90a.html

- $\$ 903$ BGB: http://www.gesetze-im-internet.de/bgb/_903.html

- Art. 333 CC: https://boe.es/buscar/act.php?id=BOE-A-1889-4763

- Art. 511-1.3 CCCat: https://www.boe.es/eli/es-ct/1/2006/05/10/5/con

- Code rural L214-1 https://www.legifrance.gouv.fr/codes/id/LEGISCTA000022200247/

- Convenio Europeo sobre la Protección de los Animales en las Explotaciones Ganaderas (10 de marzo de 1976): https://www.coe.int/en/web/conventions/full-list//conventions/rms/0900001680076da6

- Diario de Sesiones del Congreso de los Diputados, pleno y diputación permanente, Año 2021, No 96, XIV Legislatura, sesión plenaria $\mathrm{N}^{\circ}$ 92, martes, 20 de abril de 2021, págs. 17-33. https://www.congreso.es/public_oficiales/L14/CONG/DS/PL/DSCD-14-PL-96.PDF\#page=26

- Diario de Sesiones del Congreso de los Diputados, pleno y diputación permanente, Año 2017, No 29, XII Legislatura, sesiónplenaria $\mathrm{N}^{\mathrm{o}}$ 27, martes, 14 de febrero de 2017, págs. 43-50. http://www.congreso.es/public_oficiales/L12/CONG/DS/PL/DSCD-12-PL-29.PDF

- Ley 32/2007, de 7 de noviembre para el cuidado de los animales, en su explotación, transporte, experimentación y sacrificio: https:/www.boe.es/eli/es/1/2007/11/07/32/con

- Ley 7/2020, de 31 de agosto, de Bienestar, Protección y Defensa de los Animales de Castilla-La Mancha, «BOE» núm. 296, de 10 de noviembre de 2020: https://www.boe.es/diario_boe/txt.php?id=BOE-A-2020-13916

- Ley Orgánica de Educación 3/2020 de 30 de diciembre, Apartado i) del art. 17. BOE nº340 de 30 de 
diciembre de 2020 https://www.boe.es/eli/es/lo/2020/12/29/3

- Proposición de Ley de modificación del Código Civil, la Ley Hipotecaria y la Ley de Enjuiciamiento Civil sobre el régimen jurídico de los animales. BOGC de 13 de Octubre de 2017 (122/00034). http://www.congreso.es/public_oficiales/L12/CONG/BOCG/B/BOCG-12-B-167-1.PDF\#page=1

- Proposición de Ley de modificación del Código Civil, la Ley Hipotecaria y la Ley de Enjuiciamiento Civil, sobre el régimen jurídico de los animales, presentada por el Grupo Parlamentario Socialista, publicada en el «BOCG. Congreso de los Diputados», serie B, núm. 157-1, de 26 de marzo de 2021. https://www.congreso.es/public_oficiales/L14/CONG/BOCG/B/BOCG-14-B-157-1.PDF\#page=1

- Reglamento (CE) $\mathrm{n}^{\mathrm{o}} 1 / 2005$ del Consejo, de 22 de diciembre de 2004: https://eurlex.europa.eu/legal-content/ES/TXT/?uri=celex\%3A32005R0001

- TFUE, art. 13: https://eur-lex.europa.eu/legal-content/ES/TXT/?uri=CELEX:12016E013

\section{Bibliografía}

- AAVV, Les animaux, en Pouvoirs. Revue Française d'études constitutionnelles et politiques 131 (2009/4) 1-209

- ANTOINE, S., Le projet de réforme du droit des biens, en RSDA 1 (2009) 11ss.

- ARIAS, G., Comentario critico sobre la Sentencia de las actuaciones que se siguieron en el Juzgado de Primera Instancia núm. 32 de Barcelona con el número de autos 466/07 (16.5.2007) en dA. Derecho Animal (Forum of Animal Law Studies) 1/1 (2010) 1ss. https://doi.org/10.5565/rev/da.236

- ATTERTON P., CALARCO, M., Animal Philosophy. Ethics and Identity (London-New York 2004)

- BECK, A., The Biology of the Human Animal Bond, en Animal Frontiers 4/3 (2014) DOI:10.2527/af.2014-0019

- BENTHAM, J., An Introduction to the Principles of Moral and Legislation (Adamant Media Corpòration, London 2005)

- BERTUZZI, N., I movimenti animalisti in Italia. Strategie, politiche e pratiche di attivismo (Milano 2018)

- BOUdOU, B., Montaigne et les animaux (Paris 2016)

- BURGAT, F., (dir.), L'animal dans nos sociétés, La documentation Française, coll. Problèmes économiques et sociaux (2004) 11ss.

- CAPOGROSSI COLOGNESI, L., Das Eigentum in Rom vom Ende der patriarchalischen Ordnung bis zur Blütezeit der Sklavereiordnung, en Scritti scelti (Roma 2010) 299-323.

- CARDILli, R., PORCELLI, S., Introduzione al diritto cinese (Torino 2020)

- CASAS DÍAZ, L., CAMPS I VIDELLET, X., Las crisis matrimoniales y los animales de compañía: una aproximación práctica desde el ejercicio de la abogacía, en dA. Derecho Animal (Forum of Animal Law Studies) 10/1 (2019) 76-83. https://doi.org/10.5565/rev/da.397

- CERDEIRA BRAVO DE MANSILLA, Entre personas y cosas: los animales, ¿como tertium genus?", en Revista de Derecho Privado, 3 (2020) 113-128.

- CERDEIRA BRAVO DE MANSILLA, Clínicas veterinarias y paseos con animales de compañía ante el COVID-19: una actividad esencial para el bienestar del animal como ser sintiente, dA. Derecho Animal (Forum of Animal Law Studies) 11/2 (2020). DOI https://doi.org/10.5565/rev/da.499

- CERDEIRA BRAVO DE MANSILLA, G., ¿Un nuevo Derecho civil para los animales?: Elogio (no exento de enmiendas) a la nueva Proposición de Ley sobre el régimen jurídico de los animales, en España, dA. Derecho Animal (Forum of Animal Law Studies) 12/2 (2021).

- CHAPOUTHIER, G., Qu'est-ce que l'animal? (Paris 2004)

- CHAPOUTHIER, G., KAPLAN, F., L'homme, l'animal et la machine (Paris 2011)

- CUERDA ARNAU, ML (dir.), PERIAGO MORANT, JJ (coord.), De animales y normas. Protección animal y derecho sancionador (Valencia 2021)

- DARWIN, Ch., On the Origin of Species ( $1^{\mathrm{a}}$ ed. London 1859)

- DE FONTENAY, E. Le silence des bêtes (Paris 1998)

- DE TORRES PEREA, JM., El nuevo estatuto jurídico de los animales en el Derecho civil: de su cosificación a su reconocimiento como seres sensibles (Madrid 2020)

- DUNCAN-JONES, R., Structure \& Scale in the Roman Economy (Cambridge University Press 1990)

- ERNIQUIN, T., Les animaux vivants et la libre circulation: un statut de merchandises sensibles, en 
Revue des Affaires Europeennes 24 (2017) 49ss.

- FINLEY, M.I., Ancient Economy (California University Press 1999)

- FRASCH, P. (et alt.), Animal Law in a nutshell (Ann Arbor, Michigan 2011) 4ss

- FRUCTUOSO, I., Los animales y las medidas coercitivas de carácter procesal (Valencia 2021) en prensa.

- GIMÉNEZ-CANDELA, T., Derecho Privado Romano (Valencia 2020)

- GIMÉNEZ-CANDELA, M., Transición animal en España (Valencia 2020)

- GIMÉNEZ-CANDELA, T., Una nueva Revolución Francesa: la modernización del Code civil, dA. Derecho Animal (Forum of Animal Law Studies) 6/1 (2015) 1-2. https://doi.org/10.5565/rev/da.270

- GIMÉNEZ-CANDELA, M., La Descosificación de los animales (I), en dA. Derecho Animal (Forum of Animal Law Studies) 8/2 (2017) 1ss. https://doi.org/10.5565/rev/da.318

- GIMÉNEZ-CANDELA, M., La Descosificación de los animales (II), en dA. Derecho Animal (Forum of Animal Law Studies) 8/3 (2017) 1ss. https://doi.org/10.5565/rev/da.250

- GIMÉNEZ-CANDELA, M., Dignidad, Sentiencia, Personalidad: relación jurídica humano-animal, en dA, Derecho Animal, (Forum of Animal Law Studies) 9/2 (2018) 5-16. https://doi.org/10.5565/rev/da.346

- GIMÉNEZ-CANDELA, M., Descosificación de los animales en el Código civil español, en dA. Derecho Animal (Forum of Animal Law Studies) 9/3 (2018) https://doi.org/10.5565/rev/da.361

- GIMÉNEZ-CANDELA, M., Animales en el Código civil español: una reforma interrumpida, dA. Derecho Animal (Forum of Animal Law Studies) 10/2 (2019). DOI https://doi.org/10.5565/rev/da.438

- GIMÉNEZ-CANDELA, M., Tratamiento jurídico de los peces en la UE y en España, dA. Derecho Animal (Forum of Animal Law Studies) 10/4 (2019) 45-59. https://doi.org/10.5565/rev/da.475

- GIMÉNEZ-CANDELA, M., Abejas y Covid-19: una regulación jurídica necesaria, dA. Derecho Animal (Forum of Animal Law Studies) 11/4 (2020) 9-19. https://doi.org/10.5565/rev/da.558

- GIMÉNEZ-CANDELA, M., M., SARAIVA, J.L., BAUER, H., The legal protection of farmed fish in Europe - analysing the range of EU legislation and the impact of international animal welfare standards for the fishes in European aquaculture, dA. Derecho Animal (Forum of Animal Law Studies) 11/1 (2020) 65-119. https://doi.org/10.5565/rev/da.460

- GISIE, L., Comentario jurídico de la Ley 7/2020, de 31 de agosto, de Bienestar, Protección y Defensa de los Animales de Castilla-La Mancha. [2020/6154] - Diario Oficial de Castilla-La Mancha de 07-09-2020, en dA. Derecho Animal (Forum of Animal Law Studies) 12/1 (2021). DOI https://doi.org/10.5565/rev/da.556

- GÓMEZ MALDONADO, L.D., Abejas y otros insectos polinizadores frente al uso indiscriminado de Neonicotinoides y Fipronil en Colombia. Comentarios a la sentencia del 12 de diciembre de 2019 del Tribunal Administrativo de Cundinamarca, dA. Derecho Animal (Forum of Animal Law Studies) $12 / 2$ (2021)

- GONTIER, T., Intelligence et vertus animales: Montaigne lecteur de la zoologie antique, en Rursus 2 (2017) $5 \mathrm{ss}$

- GRIMALDI, M., L'exportation du code civil, en Pouvoirs. Revue française d'études constitutionnelles et politiques 107 (2003/4) 80-96.

- GUAZZALOCA, G., Primo: non maltrattare. Storia della protezione degli animali in Italia (BariRoma 2018)

- GUICHET, J.L., Rousseau, L'animal et l'homme. L'animalité dans l'horizon anthropologique des Lumières (Paris 2006)

- HALPÉRIN, J.L., L'Histoire de la fabrication du Code. Le Code Napoleon, en Pouvoirs. Revue Française d'études constitutionelles et politiques 107 (2003/4) 11ss.

- HALPERIN, J.L., Histoire du Droit des Biens (Paris 2008)

- HEUMANN, H., SECKEL, E., Handlexikon zu den Quellen des römischen Rechts (1 $11^{\mathrm{a}}$ ed. Graz 1971)

- JALUZOT, B., Les origines du code civil japonais, en Zeitschrift für Japanisches Recht Journal of Japanese Law (2015) 121-146

- JONES, R. C., Science, sentience, and animal welfare. Biology and Philosophy (2013), 1-30 DOI 10.1007/s10539-012-9351-1

- LE BOT, O., La protection de l'animal en droit constitutionnel. Etude de droit comparé, en RRJ $2007 / 4,1823 \mathrm{ss}$ 
- LELANCHON, L., La reforma del estatuto jurídico civil de los animales en el Derecho francés, en dA. Derecho Animal (Forum of Animal Law Studies) 9/3 (2018) https://doi.org/10.5565/rev/da.344

- LI, P., Animal Welfare in China (Sidney University Press 2021)

- MANNUCCI, E.J., La cena di Pitagora. Storia del vegetarianismo dall'antica Grecia a Internet (Roma 2008)

- MARGUÉNAUD, J.P. Avant-Propos, en RSDA 1 (2009) 7ss.; ANTOINE, S., Le projet de réforme du droit des biens, en RSDA 1 (2009) 11ss.

- MARGUÉNAUD, J.P., L'entrée en vigueur de "l'amendement Glavany": un grand pas de plus vers la personnalité juridique des animaux, RSDA 2/2014, 15 ss.

- OGUZ, A., The Role of Comparative Law in the development of Turkish Civil Law, en Pace Int'l L. Rev. 17 (2005) 373-386.

- OLIVERA OliVA, M., La tenencia compartida de un animal doméstico como ser sintiente. Comentario a la sentencia de fecha 27 de mayo de 2019 del Juzgado de Primera Instancia $n^{\circ} 9$ de Valladolid. Magistrado-juez: D. Luis C.Tejedor Muñoz, en dA. Derecho Animal (Forum of Animal Law Studies) 10/4 (2019) 155-158. https://doi.org/10.5565/rev/da.467

- OLIVERA OLIVA, M., Crisis de pareja de hecho y animales de compañía. Sentencias en Cataluña, anteriores a la propuesta de reforma del Código Civil de 20 de abril de 2021, dA. Derecho Animal (Forum of Animal Law Studies) 12/2 (2021)

- OLMEDO DE LA CALLE, E., Los delitos de maltrato animal en España (Valencia 2021)

- PETERS, A., Liberté, Egalité, Animalité, en Transnational Environmental Law 5/1 (2016) 25ss. DOI: https://doi.org/10.1017/S204710251500031X

- PETERS, A., Animals in International Law. Hague Academy of International Law. Offprint from the Recueil des cours, 140 (Leiden-Boston 2020)

- POLLO, S., Umani e Animali. Questioni di Etica (Roma 2016)

- POLlO, Manifesto per un animalismo democratico (Roma 2021)

- PROCTOR, H., S., CARDER, G., CORNISH, A. R., Searching for Animal Sentience: A Systematic Review of the Scientific Literature, en Animals, 3/3 (2013) 882-906. DOI: https://doi.org/10.3390/ani3030882

- PROCTOR, H., Animal Sentience: Where Are We and Where Are We Heading?, en Animals 2/4 (2012) 628-639 DOI: https://doi.org/10.3390/ani2040628

- RATHBONE, D., Rural Economy and Society in Roman Italy (Cambridge University Press 2004)

- REGAN, T., The Case for Animal Rights (Berkeley 1983)

- REMESAL RODRÍGUEZ, J., Heeresversorgung im frühen Prinzipat. Eine Art, die antike Wirtschaft zu verstehen. (Münster 2002)

- ROGEL VIDE, C., Personas, animales y Derechos (Madrid-México 2018)

- ROGEL VIDE, C., Los animales en el Código Civil (Madrid 2017)

- ROGEL VIDE, C., Personas, animales y androides, en RGLJ, 4 (2017) pp. 681-693

- SCHEIDEL, W., von REDEN, S. (ed.) The Ancient Economy (Princeton 2002)

- SCHERMAIER, M., Dominus actuum suorum. Die willenstheoretische Begründung des Eigentums und das römische Recht, en SZ 134 (2017) 50ss.

- SCHERMAIER, M., Der zivilrechtliche Eigentumsbegriff in historischer Perspektive: Die beiden Gesichter des $\S 903$ BGB, en BRINKMANN, M., SHIRVANI, F., Privatrecht und Eigentumsrecht (Baden-Baden 2016), 23-62

- STAMP DAWKINS, M., The Science of Animal Welfare. Understanding whay animals want (Oxford 2021)

- VILlalBA, T., Código de Protección y Bienestar Animal (BOE 2021). https://www.boe.es/biblioteca_juridica/codigos/codigo.php?id=204_Codigo_de_Proteccion_y_Bie nestar_Animal\&modo $=2$

- WEBER, M., Wirtschaft und Gesellschaft: Grundriß der verstehende Soziologie/Max Weber; besorgt von Johannes Winckelmann (Tübingen 1985) 